\title{
The Precautionary Role of Nigella Sativa Oil in Methimazole Associated Toxicity on the Structure of Spleen in Adult Male Albino Rats: Histological, Hematological and Morphometric Study
}

\author{
Original \\ Article \\ Marwa M. Ahmad', Manal Mohammad Morsy' ${ }^{1}$ and Reham Mohamed Morsi ${ }^{2}$ \\ ${ }^{I}$ Department of Human Anatomy, Faculty of Medicine, Zagazig University, Egypt. \\ ${ }^{2}$ Biological Applications Dept., Radioistopes Applications Division, Nuclear Research Center, \\ Egyptian Atomic Energy Authority
}

\begin{abstract}
Background: Methimazole (MMZ), has been the drug of choice in treatment of human hyperthyroidism for several decades, however its administration may result in unfavorable effects. The spleen can reflect this drug induced immune-toxicity. Nigella sativa oil (NSO) has potent immune-protective action.

Aim: The current study aimed to determine the alternation in the structure of the spleen and hematological parameters as a result of MMZ administration and if NSO has protective role in such case.

Materials and Methods: The study was conducted on twenty five adult male albino rats, divided into five groups ( $\mathrm{n}=5$ ), group I served as control, group II received $0.25 \mathrm{ml} / \mathrm{kg} /$ day of NSO started two weeks before the experiment and continue till its end (for 6 weeks), group III subjected to surgical thyroidectomy, group IV rats treated with MMZ ( $20 \mathrm{mg} / \mathrm{kg} / \mathrm{day})$ and group V pretreated with NSO for 2 weeks and then accompanied with MMZ for 4 weeks in the same dose of group II and IV respectively. At the end of the experiment, spleen specimens were taken and processed for H\&E and immunohistochemical stains (CD4and Ki67) in addition to hematological analysis.

Results: Remarkable alternations in the structure of the spleen were noticed in rats treated with MMZ. Moreover, RBCs and WBCs counts were reduced in MMZ- treated group. NSO co- administration with MMZ revealed partial improvement in histological structure of the spleen and blood picture.

Conclusion: MMZ drug has an obvious immuntoxic effect on the spleen and NSO has relevant protective action.
\end{abstract}

Key Words: Methimazole, Nigella sativa oil, spleen

Revised: 15 September 2019, Accepted: 23 September 2019.

Corresponding Author: Marwa M. Ahmad, MD, Anatomy and Embryology Department, Faculty of Medicine, Zagazig university, Sharkia, Egypt, Tel.: 01066500159, E-mail: marwaahmed515@gmail.com

ISSN:2536-9172, December 2019, Vol. 3, No. 2

\section{INTRODUCTION}

Anti- thyroid drugs (ATDs) have been fundamental in the management of human hyperthyroidism for several years $^{[1]}$. Several studies stated that the use of ATDs can result in cellular damage ${ }^{[2-3]}$. One of the most commonly used ATDs was Methimazole (MMZ); drug that is chemically a thioamide derivative ${ }^{[4]}$. Many reports stated that thionamide group of the anti-thyroid drugs is greatly responsible for the unfavorable effects of such drugs ${ }^{[5]}$.

MMZ action is to stop synthesis of thyroid hormone through interfering with thyroid peroxidase-mediated thyroglobulin organification ${ }^{[6]}$. Although $\mathrm{MMZ}$ is an efficient anti-thyroid drug but its administration is associated with many hazardous effects such as nephrotoxicity, cholestasis, liver damage, loss of taste and smell, skin rash and teratogenicity ${ }^{[7]}$.

There are many theories that can explain MMZ toxicity, including reactive metabolites formation, immune-mediated, and oxidative stress induction ${ }^{[8]}$.
Reactive intermediates of MMZ metabolism include $\mathrm{N}$-methylthiourea and glyoxal which have important role in induction of cellular dysfunction and oxidative stress ${ }^{[9-10]}$. The oxidative stress state resulted from disruption of balance between oxidants and antioxidants reducing the anti-oxidative defense capacity of the cells and makes the antioxidant system unable to neutralize the oxidants resulting in lipid peroxidation and subsequent increase in reactive oxygen species $(\mathrm{ROS})^{[11]}$.

The immune system is the result of collaboration between different types of cells; which are in continuous state of proliferation and differentiation, in addition to various organs that functioning together to generate adequate immune response ${ }^{[12]}$. Spleen as a part of the immune system is susceptible to adverse drug immunotoxicity through different ways such as oxidative stress, immunesuppression or stimulation and autoimmunity ${ }^{[13]}$.

Immunosuppression doesn't affect spleen only but also suppress erythropoiesis process within the bone marrow which in turn reflected on the blood picture ${ }^{[14]}$. 
One of the reported toxic effects of MMZ was agranulocytosis; which defined as severe and dangerous leukopenia (agranulocyte count below $500 \backslash \mathrm{L}$ ) ${ }^{[15]}$. Previous study stated that anti-granulocyte autoantibodies are commonly revealed in patients administrating ATDs, which greatly reflect the MMZ immune-mediated toxicity ${ }^{[16]}$.

Nigella sativa is a natural plant belonging to Ranunculaceae family and available in many countries (such as Middle East and Western Asia).Its seeds have been used in traditional medicine for years, also its oil extract is known to have precautionary role in a variety of diseases ${ }^{[17]}$. Thyamoquinone is one of the main ingredients of nigella sativa oil (NSO) and known with its potent immunomodulatory role ${ }^{[18]}$.

Few studies addressed the immuotoxicity as a consequence of MMZ administration. Thus, the aim of this study was to assess the effect of MMZ on the histological structure of spleen and on hematologic parameters in rats and evaluating the possible precautionary role of NSO as anti-immunohematotoxic agent.

\section{MATERIALS AND METHODS}

\section{Drugs:}

Methimazole (MMZ) CAS No. 60-56-0 purchased from (Sigma Chemical Co., UK) and nigella sativa oil (NSO); brown to deep brown free flowing liquid CAS Number: 90064-32-7was purchased from Kahira Pharmaceuticals \& Chemical Industries Company, Zagazig, Egypt.

\section{Animals and experimental design:}

The study was conducted on twenty five adult male albino rats weighting 180-200 gm. Animals were purchased from the Zagazig Scientific and Medical Research center (ZSMR), Faculty of Medicine, Zagazig University. All rats were kept under hygienic conditions. Standard food and water were allowed. All rats were handled in accordance to the standard guideline for the care and use of laboratory animal, Zagazig University. The animals were housed in plastic cages with stainless steel wire-bar lid and maintained under standard laboratory conditions at $23 \pm 1{ }^{\circ} \mathrm{C}$, relative humidity $55 \pm 5 \%$ and photoperiod of $12 \mathrm{~h}$-dark and light. After one week of adaptation, rats were divided randomly into five groups (five rats each):

Group I (control group): served as control group and received only standard diet.

Group II (NSO group): animals of this group received $0.25 \mathrm{ml} / \mathrm{kg} /$ day of NSO 2 weeks before the experiment and continue till its end ${ }^{[17]}$.

Group III (thyroidectomy group): to induce hypothyroidism animals subjected to surgical thyroidectomy; in which animals were anaesthetized with sodium pentobarbital intra-peritoneal $(35 \mathrm{mg} / \mathrm{kg}$ body weight) then the trachea was exposed after the sternothyroid muscle had been cut.

Parathyroid glands were isolated from the thyroid gland, and implanted into the surrounding muscle. The thyroid gland was dissected gently with great care to laryngeal nerve then excised after the operation, rats received (ketolac $50 \mathrm{mg} / \mathrm{kg}$ i.m.) and gentamicin $(10 \mathrm{mg} /$ $\mathrm{kg}$ ) to relieve pain and protect against infection for five days ${ }^{[19]}$.

Group IV (MMZ-treated group): rats were treated with methimazole (MMZ) in dose of $20 \mathrm{mg} / \mathrm{kg} /$ day dissolved in distilled water for 4 weeks ${ }^{[20]}$.

Group V (MMZ+NSO group): rats were pretreated with the for-mentioned dose of NSO for two weeks and then accompanied with MMZ in the same dose of group IV for the following 4 weeks.

\section{Body weight:}

At the beginning of the experiment, the initial body weights of the animals were recorded, and then the final body weights were listed for statistical analysis.

\section{Hormonal assessment:}

Serum levels of the thyroid hormones (T3 and T4) at the end of the treatment were assessed using solidphase radioimmunoassay technique (All reagents needed for determination of total T3 and T4 were packaged in a commercial kit supplied from Diagnostics Products Corporation (DPC), Los Angeles, CA 90045-6900, USA) to confirm the hypothyroid state ${ }^{[21]}$.

\section{Hematological parameters:}

The blood samples for hematology and biochemical analysis were withdrawn at the end of the treatment under pentobarbital anesthesia from retro-orbital venous plexus. Red (RBC's) and white blood cell (WBC's) counts, hemoglobin (HGB), hematocrit (HCT), mean corpuscular volume (MCV), mean corpuscular hemoglobin $(\mathrm{MCH})$, mean corpuscular hemoglobin concentration $(\mathrm{MCHC})$ and platelet (PTL) count, were determined using an automated hematology analyzer K-4500, Sysmex Corp., Hyogo, Japan). Under light microscopy, blood smears stained with Wright Giemsa stain; differential leukocyte counts were calculated for 100 leukocytes per rat ${ }^{[22]}$.

\section{Light microscopy technique}

At the end of the experiment, all animals were anaesthetized, their abdominal cavities were opened spleens were dissected and immersed at once in $10 \%$ formol saline for 48 hours to be Processed and embedded 
in paraffin. Coronal cuts of $5 \mu \mathrm{m}$ thicknesses were cut by a standard microtome then stained with $H \& E^{[23]}$

The spleen immunohistochemictry was performed using Anti CD4 antibody (PE Mouse Anti-Rat CD4 catalog No. 550296, dilution 1:20 ;BD Biosciences, USA) which appear as brownish cytoplasmic granules and anti Ki67 antibody (rabbit poly-clonal antibody; No. ab15580; dilution $1 \mu \mathrm{g} / \mathrm{ml}$; Abcam, Cambridge, UK) with nuclear reaction for demonstration of $\mathrm{T}$ - helper lymphocytes and proliferating cells respectively. The paraffn-embedded tissue sections $(5 \mu \mathrm{m}$ thick) were deparaffnized and dehydrated. Hydrogen peroxide $0.05 \%$ used for $30 \mathrm{~min}$, to block the endogenous Peroxidase activity, then the slides were washed in PBS of $\mathrm{pH} 7.4$ for $5 \mathrm{~min}$. Sections were placed in $0.01 \mathrm{~mol} / \mathrm{l}$ citrate buffer $(\mathrm{pH}$ 6)in a microwave for $10 \mathrm{~min}$ to unmask the antigenic sites. The sections were incubated with CD4 and Ki67 (primary antibodies) except for the negative control. The slides were incubated for $1.5 \mathrm{~h}$ at room temperature then rinsed with PBS and incubated for $1 \mathrm{~h}$ with anti-mouse immunoglobulins) secondary antibody) conjugated to peroxidase-labeled dextran polymer (Dako, Denmark). The slides were incubated in 3, 3-diaminobenzidine for $15 \mathrm{~min}$ to detect the reaction. Finally the slides were counterstained with H\&E, dehydrated and cleared ${ }^{[24]}$.

\section{Morphometric study:}

The surface areas $(\mu \mathrm{m} 2)$ of lymphatic follicles, diameter of lymphatic follicles $(\mu \mathrm{m})$, marginal zone thickness $(\mu \mathrm{m})$ were measured in Haematoxylin and Eosin stained sections. Also the mean number of positive cell of CD4 and Ki67 in Immunohistochemical stained sections. Detection of number of the germinal center per transverse section in Haematoxylin and Eosin stained sections. Lymphatic follicles surface areas and diameters were measured on equally magnified images (x100) while marginal zone thickness measured on equally magnified images (x400) captured from H\&E stained sections. The digital photos were captured in the Microscopic Photography Unit (Anatomy Department, Faculty of Medicine, Zagazig University) using a Canon Power Shot A640 digital camera (Japan). Fifty different relevant fields from each animal group were selected randomly. The measurements were performed using Digimizer PC image analysis software (Leica Q 500 MC program,Wetzlar, Germany).

\section{Statistical analysis:}

The variables measured were recorded and tabulated, the mean and SD were calculated for each animal group. Analysis of variance tests (ANOVA) and Tukey's post hoc test were used to compare the measurements between groups. Calculations were carried out using SPSS, version 0.9 SPSS Inc., Chicago, Illinois, USA). P value was considered significant if $\mathrm{P}$ value was less than 0.05 .

\section{RESULTS}

\section{Body weights:}

Thyroidectomy and MMZ- treated groups showed significant reduction in final body weights when compared with control and NSO groups. However, assessment of body weights in MMZ+NSO group resulted in recuperation of almost normal body weights levels (table 1 ).

\section{T3\& T4 results (thyroid hormones)}

In comparison with control and NSO groups, thyroidectomy and MMZ- treated groups revealed significant reduction in T3\&T4 levels. On the other hand, MMZ+NSO group showed normal levels of thyroid hormones (table 2).

\section{Hematological results:}

The hematological examination of MMZ- treated group showed significant decline in RBC's counts when compared with all tested groups. MMZ+NSO group showed improvement in RBC's counts when compared with MMZtreated group. In respect to hemoglobin concentration, MMZ- treated group showed highly significant decrease in comparison with control groups and NSO administration in combination with MMZ resulted in significant elevation compared with MMZ- treated group.

Regarding $\mathrm{MCH}, \mathrm{MMZ}$ - treated group showed significant increase when compared with control groups, but no significant change was detected between MMZtreated group and MMZ+NSO group. In addition, $\mathrm{MCHC}$ recorded significant increase in MMZ- treated group in comparison with control, NSO and thyroidectomy groups and co-administration of NSO restored it nearly to its normal levels.

In addition, WBC's count and lymphocytes were significantly lower in MMZ- treated group when compared with all other tested groups and in MMZ+NSO group they recorded almost normal counts.

Monocytes and neutrophils showed also significant decrease in MMZ- treated group when compared with all tested groups. Administration of NSO in combination with MMZ resulted in significant elevation to be almost close to control levels (table 3).

\section{Histological results:}

\section{Control group (group I)}

Examination of Haematoxylin and Eosin stained sections from control group (group I) showed typical spleen architecture with its characteristic two main components; 
white pulps (lymphoid tissue) which embedded in red pulps) vascular matrix) and A marginal zone (MZ) appeared to demarcate the splenic white lymphoid pulps from the red non-lymphoid pulp (Fig. 1A). The white pulp appeared to consist of lymphoid follicles. Each lymphoid follicle had central arteriole and surrounded by periarterial lymphatic sheath (PALS) containing large number of the lymphocytes (Fig. 1B). The red pulp was formed of splenic blood sinusoids intervening between branching and anastomosing splenic cords (Fig. 1C).

Nigella sativa oil group (Group II) and thyroidectomy group (group III) showed almost the same histological features of group I.

\section{MMZ-treated group (group IV)}

Examination of MMZ- treated group (group IV) showed marked histological changes when compared to the control group.The white pulp showed disturbed arrangement with well- developed germinal centers and the marginal zones appeared indistinct ill-defined and depleted of lymphocytes compared with the control group (Fig. 1D). Numerous areas contained debris of ruptured degenerated cells, vacuolated cells; in addition to areas containing acidophilic cells with fragmented pyknotic nuclei were noticed (Fig. 1E). Also, the white pulp showed thickened wall of central arteriole .The red pulp contained dilated congested splenic sinuses (Fig. 1F).

\section{$M M Z+N S O$ group (group $V$ )}

Examination of MMZ+NSO group (group V) demonstrated a significant improvement in the form of restoration of splenic architecture, preservation of Lymphocytes of the white pulp that appeared closer to the normal and the marginal zones were apparent and well defined (Fig. 1G, H). The red pulp appearance showed almost normal architecture (Fig.1I) however, degenerated areas were still detected.

\section{Immunohistochemical results:}

Group I, II and III stained sections with CD4 revealed large number of CD4 positive cells with positive brownish cytoplasmic immuno reaction mainly in lymphocytes of the white pulp, particularly in PALS and also in marginal zones in addition to splenic cords of the red pulps (Fig. 2A.). In the Group IV (MMZ- treated group), an apparent decrease of the number of CD4 positive cells was observed in the specimen. Only a few faintly stained CD4+ cells were scattered in the PALS and in marginal zones (Fig 2B), while in the Group V (MMZ+NSO) group, immunoreaction of CD4 was slightly increased when compared with that of MMZ-treated group (Fig. 2C).

Sections stained with Ki67 in control group showed few number of Ki67+ve stained cells (Fig. 3A), while in MMZ-treated there was apparent increase in the number of Ki67+ve stained cells especially within the germinal centers was evident (Fig. 3B). Slight decrease in Ki67+ve stained cells was noticed with combined NSO and MMZ administration (group V) (Fig. 3C).

\section{Morphometric results}

MMZ-treated group exhibited significant decrease in the lymphatic follicles surface area and diameter in comparison with control, NSO and thyroidectomy groups. While, in MMZ+NSO the lymphatic follicles recorded almost normal values. Regarding the Marginal zone thickness, MMZ-treated group showed significant reduction in marginal zone thickness, while NSO coadministration was able to return it closer to its normal values (table4).

There was a significant reduction in the number of of CD4 positive cells in MMZ- treated group in comparison with groups I, II and III. A significant increase in the number of CD4+ cell was exhibited in MMZ+NSO group. (table 4).

Marked increase in Ki67 positively stained cells was detected in MMZ treated group. Meanwhile, reduction of Ki67 positively stained cells was recorded in MMZ+NSO (table 4).

Germinal centers couldn't be detected in groups I, II and III. Rats treated with MMZ showed development of germinal centers whereas, administration of NSO significantly reduce it (table 5).

Table 1: Showing the means \pm SD of initial body weight (IBW) and Final body weight (FBW)

\begin{tabular}{llllll}
\hline & Control & Nigella sativa oil (NSO) & thyroidetomy & Methimazole (MMZ) & MMZ+NSO \\
\hline IBW $(\mathrm{gm})$ & $184.6 \pm 14.4$ & $181.1 \pm 13.3$ & $182.5 \pm 15.8$ & $180.6 \pm 15.1$ & $185.1 \pm 13.4$ \\
FBW $(\mathrm{gm})$ & $318.5 \pm 16.5$ & $320.8 \pm 17.8$ & $309.5 \pm 18.6$ & $243.8 \pm 15.6$ & $297.5 \pm 12$ \\
\hline
\end{tabular}

Table 2: Showing the means \pm SD of T3 and T4

\begin{tabular}{|l|l|l|l|l|l|l|l|}
\hline & Control & Nigella sativa oil (NSO) & Thyroidectomy & Methimazole (MMZ) & MMZ+NSO & F & P \\
\hline T3 & $1.41 \pm .01$ & $1.63 \pm .05$ & $76 \pm 0.05$ & $87 \pm 0.04$ & $1.7 \pm .07$ & 416.822 & .000 \\
\hline T4 & $6.73 \pm .22$ & $7.25 \pm .43$ & $3.69 \pm .44$ & $3.87 \pm .39$ & $7.1 \pm .32$ & 137.920 & .000 \\
\hline
\end{tabular}


Table 3: Showing the means \pm SD of red blood cell (RBC); Hemoglobin; mean corpuscular volume (MCV); mean corpuscular hemoglobin $(\mathrm{MCH})$; mean corpuscular hemoglobin concentration (MCHC); total white blood cell (WBC); Lymphocyte; Neutrophil and Monocyte in the different studied groups.

\begin{tabular}{|c|c|c|c|c|c|c|c|c|}
\hline & Control & Nigella sativa oil (NSO) & thyroidetomy & Methimazole (MMZ) & $\mathrm{MMZ}+\mathrm{NSO}$ & $\mathrm{F}$ & $\mathrm{P}$ & LSD \\
\hline $\operatorname{RBC}\left(10^{3} / \mu \mathrm{L}\right)$ & $643.6 \pm 59$ & $645.1 \pm 19$ & $640 \pm 30$ & $567.6 \pm 23$ & $621.6 \pm 29$ & 5.08 & .004 & $\begin{array}{c}<.05^{\mathrm{a}} \\
<.05^{\mathrm{b}} \\
N S^{\mathrm{c}}\end{array}$ \\
\hline $\begin{array}{l}\text { Hemoglobin } \\
(\mathrm{g} / \mathrm{dL})\end{array}$ & $\begin{array}{l}13.3 \quad \pm \\
0.85\end{array}$ & $13.2 \pm 0.73$ & $13.0 \pm .9$ & $10.7 \pm 0.97 \mathrm{c}$ & $12.1 \pm .66$ & 10.2 & .000 & $\begin{array}{l}<.001^{\mathrm{a}} \\
<.05^{\mathrm{b}} \\
<.05^{\mathrm{c}}\end{array}$ \\
\hline MCV (fL) & $60 \pm 1.2$ & $60.3 \pm 1.8$ & $60.1 \pm 2$ & $57.1 \pm 3.1$ & $59.5 \pm 1.8$ & 2.15 & .104 & $\begin{array}{c}<.05^{\mathrm{a}} \\
\mathrm{NS}^{\mathrm{b}} \\
\mathrm{NS}^{\mathrm{c}}\end{array}$ \\
\hline $\mathrm{MCH}(\mathrm{pg})$ & $21.8 \pm 1.4$ & $21.5 \pm 1$ & $21.8 \pm 1.4$ & $23.3 \pm 1.3^{*}$ & $22 . \pm 1.2$ & 1.71 & .179 & $\begin{array}{c}<.05^{\mathrm{a}} \\
\mathrm{NS}^{\mathrm{b}} \\
\mathrm{NS}^{\mathrm{c}}\end{array}$ \\
\hline $\mathrm{MCHC}(\mathrm{g} / \mathrm{dL})$ & $34.9 \pm 1.1$ & $34.8 \pm .9$ & $34.1 \pm 1.1$ & $36.9 \pm 1.3$ & $35.5 \pm 1$ & 4.95 & .004 & $\begin{array}{c}<.001^{\mathrm{a}} \\
<.05^{\mathrm{b}} \\
\mathrm{NS}^{\mathrm{c}}\end{array}$ \\
\hline $\begin{array}{l}\text { Platelet } \quad\left(10^{3} /\right. \\
\mu \mathrm{L})\end{array}$ & $987 \pm 14$ & $995 \pm 9.4$ & $990 \pm 9.7$ & $909 \pm 12.2$ & $971 \pm 8.5$ & 60.9 & .000 & $\begin{array}{l}<.001^{\mathrm{a}} \\
< \\
001^{\mathrm{b}} \\
<.05^{\mathrm{c}}\end{array}$. \\
\hline $\operatorname{WBC}\left(10^{3} / \mu \mathrm{L}\right)$ & $8.68 \pm .93$ & $8.41 \pm 1.3$ & $8.21 \pm 1.3$ & $5.21 \pm .47$ & $7.66 \pm .97$ & 10.8 & .000 & $\begin{array}{c}<.001^{\mathrm{a}} \\
<001^{\mathrm{b}} \\
\mathrm{NS}^{\mathrm{c}}\end{array}$ \\
\hline $\begin{array}{l}\text { Lymphocyte } \\
\left(10^{3} / \mu \mathrm{L}\right)\end{array}$ & $7.56 \pm .75$ & $7.4 \pm .82$ & $7.17 \pm 1$ & $4.48 \pm .34$ & $6.93 \pm .83$ & 15.726 & .000 & $\begin{array}{l}<.001^{\mathrm{a}} \\
<001^{\mathrm{b}} \\
\mathrm{NS}^{\mathrm{c}}\end{array}$ \\
\hline $\begin{array}{l}\text { Ne u trop hil } \\
\left(10^{3} / \mu \mathrm{L}\right)\end{array}$ & $.58 \pm .04$ & $.56 \pm .07$ & $.55 \pm .04$ & $.29 \pm .05$ & $.39 \pm .05$ & 33.619 & .000 & $\begin{array}{l}<.001^{\mathrm{a}} \\
<.05^{\mathrm{b}} \\
<.001^{\mathrm{c}}\end{array}$ \\
\hline $\begin{array}{l}\text { Monocyte }\left(10^{3} /\right. \\
\mu \mathrm{L})\end{array}$ & $.54 \pm .07$ & $.5 \pm .02$ & $.52 \pm .03$ & $.29 \pm .04$ & $.38 \pm .04$ & 29.463 & .000 & $\begin{array}{l}<.001^{\mathrm{a}} \\
<.05^{\mathrm{b}} \\
<.001^{\mathrm{c}}\end{array}$ \\
\hline
\end{tabular}

${ }^{a}$ Methimazole- treated group versus control or thyroidectomy groups.

${ }^{b}$ Methimazole- treated group versus protective group.

'protective group versus control or thyroidectomy groups.

Table 4: showing the means \pm SD lymphatic follicles area (LFA) $(\mu \mathrm{m} 2)$; lymphatic follicle diameter (LFD) $(\mu \mathrm{m})$; Marginal zone thickness $(\mathrm{MZT})(\mu \mathrm{m})$; mean number of positive cells of CD4 and Ki67 in the different studied groups.

\begin{tabular}{|c|c|c|c|c|c|c|c|c|}
\hline & Control & $\mathrm{NSO}$ & thyroidetomy & MMZ & $\mathrm{MMZ}+\mathrm{NSO}$ & $\mathrm{F}$ & $\mathrm{P}$ & \\
\hline $\operatorname{LFA}\left(\mu \mathrm{m}^{2}\right)$ & $164760.35 \pm 32590$ & $\begin{array}{l}159981.77 \pm \\
29806\end{array}$ & $\begin{array}{l}158699.41 \pm \\
34397\end{array}$ & $\begin{array}{l}73757.04 \pm \\
7849\end{array}$ & $\begin{array}{l}133710.79 \pm \\
48871\end{array}$ & 7.754 & .000 & $\begin{array}{l}<.001^{\mathrm{a}} \\
<.05^{\mathrm{b}} \\
\mathrm{NS}^{\mathrm{c}}\end{array}$ \\
\hline $\mathrm{LFD}(\mu \mathrm{m})$ & $410.3138 \pm 86.94171$ & $\begin{array}{l}414.4718 \pm \\
79.01010\end{array}$ & $\begin{array}{l}417.6760 \pm \\
86.90375\end{array}$ & $\begin{array}{l}248.0593 \pm \\
29.63755\end{array}$ & $\begin{array}{l}385.1492 \pm \\
62.68171\end{array}$ & 5.975 & .002 & $\begin{array}{l}<.001^{\mathrm{a}} \\
<.05^{\mathrm{b}} \\
\mathrm{NS}^{\mathrm{c}}\end{array}$ \\
\hline $\operatorname{MZT}(\mu \mathrm{m})$ & $55.50 \pm 12.59333$ & $\begin{array}{l}56.1667 \pm \\
12.41\end{array}$ & $54.33 \pm 12.19$ & $\begin{array}{l}24.31 \\
10.20\end{array}$ & $\begin{array}{l}43.97 \\
10.79\end{array}$ & 8.070 & .000 & $\begin{array}{l}<.001^{\mathrm{a}} \\
<.05^{\mathrm{b}} \\
\mathrm{NS}^{\mathrm{c}}\end{array}$ \\
\hline $\mathrm{CD}$ number & $27.33 \pm 5.3$ & $27.16 \pm 5.4$ & $27 \pm 4.6$ & $11.8 \pm 1.4$ & $22.83 \pm 3.2$ & 14.216 & .000 & $\begin{array}{l}<.001^{\mathrm{a}} \\
<. .001^{\mathrm{b}} \\
\mathrm{NS}^{\mathrm{c}}\end{array}$ \\
\hline Ki number & $5.33 \pm 1.08$ & $5.78 \pm 1.27$ & $5.38 \pm 1.30$ & $38.16 \pm 1.72$ & $11.05 \pm 1.41$ & 637.8 & .000 & $\begin{array}{l}<.001^{\mathrm{a}} \\
<.001^{\mathrm{b}} \\
<.001^{\mathrm{c}}\end{array}$ \\
\hline
\end{tabular}

${ }^{\mathrm{a}}$ Methimazole- treated group versus control or thyroidectomy groups.

${ }^{b}$ Methimazole- treated group versus protective group.

'protective group versus control or thyroidectomy groups. 
Table 5: Showing the number of animals that developed germinal centers in each group.

\begin{tabular}{llllr}
\hline Grade & - & + & ++ & ++ \\
\hline Control & 5 & 0 & 0 & 0 \\
NSO & 4 & 1 & 0 & 0 \\
Thyroidetomy & 4 & 1 & 0 & 0 \\
MMZ & 0 & 0 & 2 & 0 \\
MMZ+NSO & 0 & 3 & 0
\end{tabular}
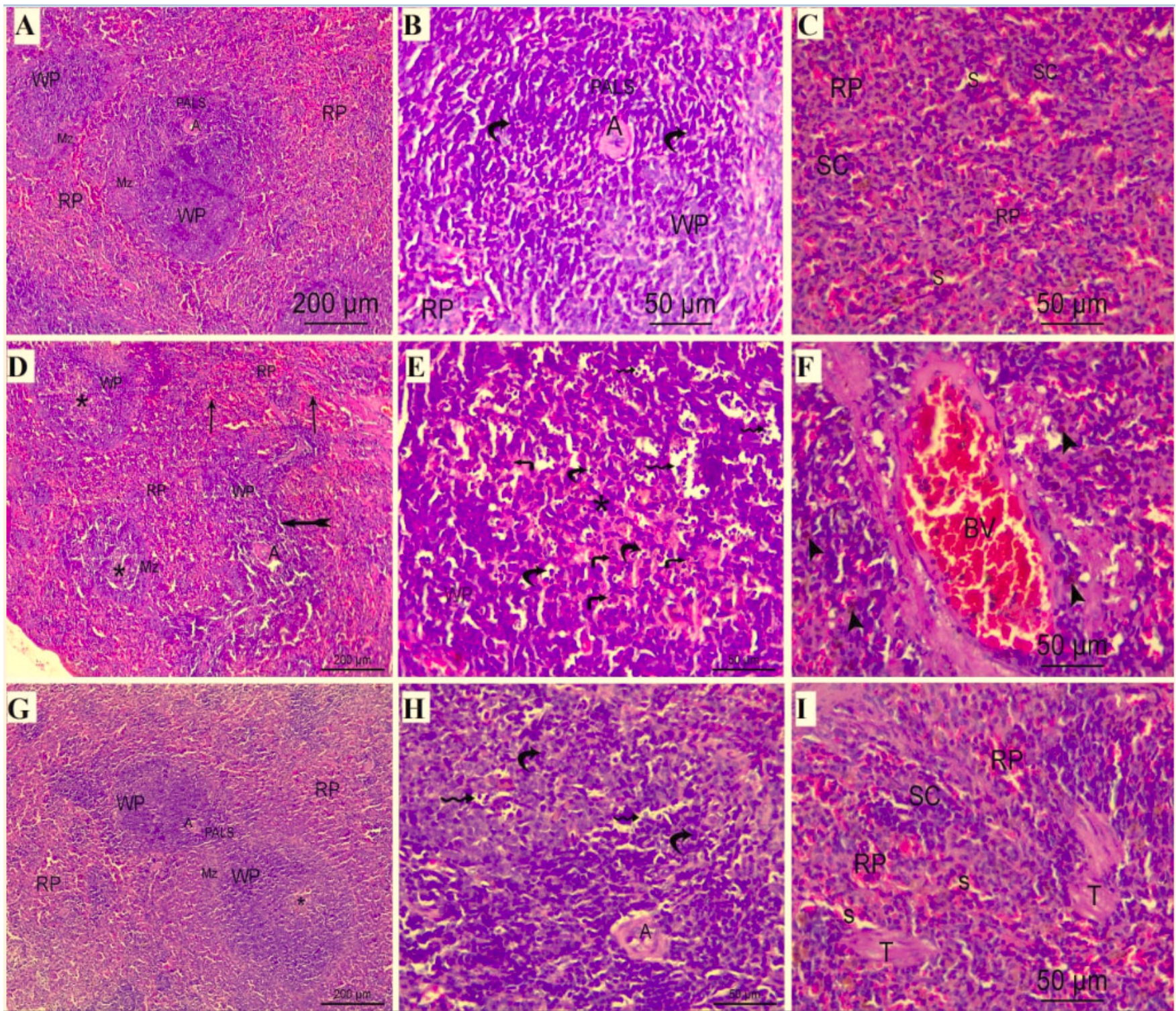

Fig. 1: Photomicrographs of the spleen sections stained with H\&E from all studied groups. 1A). control group shows its two main components white pulp (WP) and red pulp (RP) with distinct marginal zone (Mz) in between. The white pulp contains central arteriole (A) that is surrounded by peri-arterial lymphatic sheath (PALS). 1B). White pulp (WP) is formed of lymphocytes with dark stained nuclei (curved arrow). 1C). the red pulp (RP) which contains blood sinusoids (S) and splenic cords (SC).1D) MMZ-treated group showing the white pulp with disturbed lymphatic architecture (bifid tailed arrow) with appearance of germinal center (asterisk), The red pulp (RP) contains dilated congested blood sinusoids (arrow). Note ill-defined marginal zone (Mz). 1E). Showing white pulp (WP)contain area of degeneration in the form of debris of ruptured cells with fragmented nuclei (zigzag arrow), germinal center (asterisk), acidophilic cells with several fragmented pyknotic nuclei (angled arrow) and vacuolated cells with fragmented pyknotic nuclei (curved arrow). 1F). Dilated congested blood vessels (BV), hemosiderin laden cells (arrowhead) are also seen. 1G,H). In MMZ+NSO group the normal splenic architecture can be seen with preservation of Lymphocytes (curved arrow) of the white pulp (WP), however degenerated areas (asterisk ) and vacuolated cells with pyknotic nuclei (zigzag arrow) are still detected 1I). The red pulp (RP) appearance is almost normal that containing blood sinusoids (S) and splenic cords (SC). Note presence of splenic trabecula (T)

[H\&E, A,D,G X100; B,C,E,F,H,I x400]. 

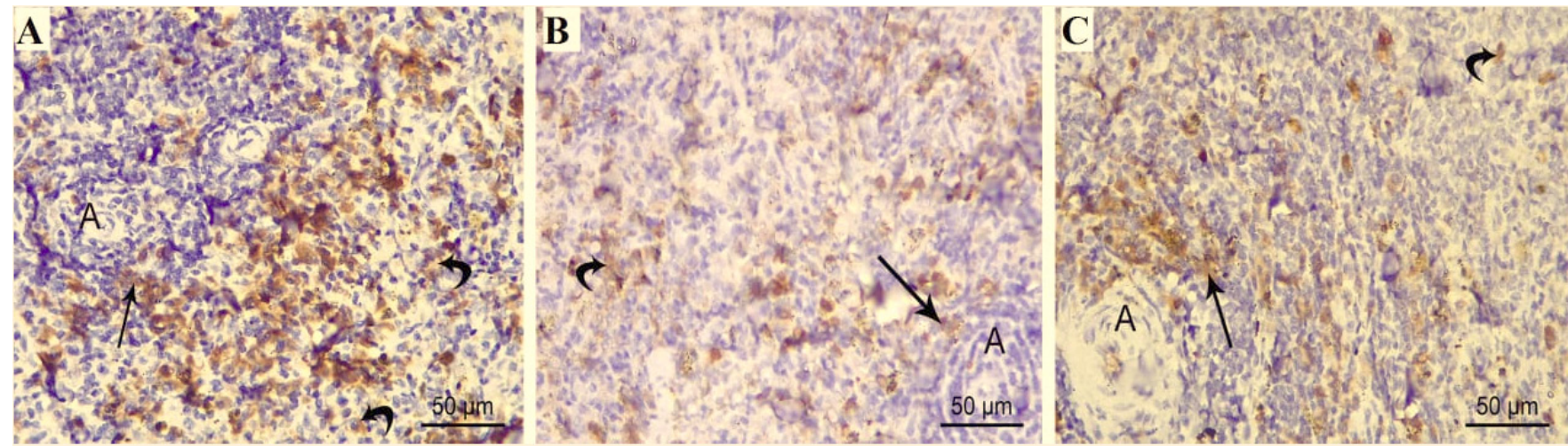

Fig. 2: Photomicrographs of spleen sections stained anti-CD4 in different experimental groups. 2A). control groups showing white pulp central arteriole (A) surrounded by cells with large number of CD4 positive cells; with brownish cytoplasmic granules; especially in periarterial lymphatic sheath (arrow) and in marginal zones (curved arrow). 2B). MMZ-treated group shows marked reduction in the number of CD4+ cells in both periarterial lymphatic sheath (arrow) and marginal zones (curved arrow). 2C). MMZ+NSO group shows slight increase in $\mathrm{CD} 4+$ cells in periarterial lymphatic sheath (arrow) and marginal zones (curved arrow).

[immunostaining CD4, × 400].
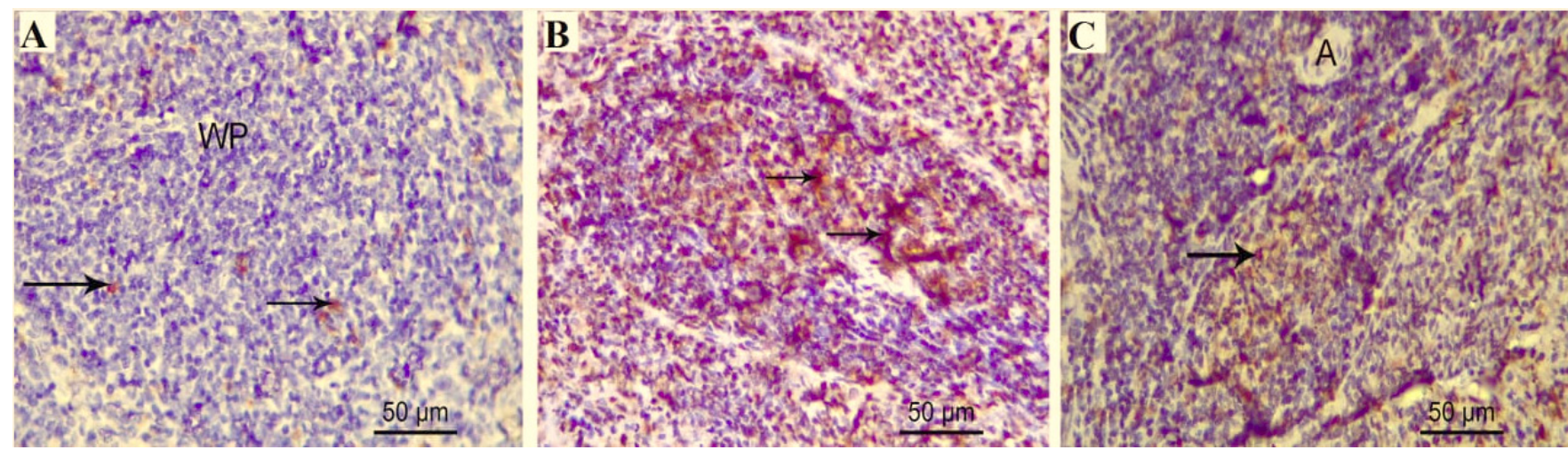

Figure 3: Photomicrographs of spleen sections stained anti-Ki67 in different experimental groups. 3A) control groups showing few number of Ki67+ve stained cells (arrow) in white pulp (WP).3B). MMZ-treated group shows apparent increase in the number of Ki67+ve stained cells especially within the germinal center (arrow).3c). MMZ+NSO group reveals slight reduction in the number of Ki67+ve stained cells (arrow).

[immunostaining Ki67, X400].

\section{DISCUSSION}

Methimazole (MMZ) is a very popular and effective anti-thyroid drug, but its administration is associated with many adverse effects ${ }^{[25]}$. The current study was performed to evaluate the immuotoxic effect of MMZ in rat's spleens after 4 weeks of oral administration.

In the present work, rats treated with $\mathrm{MMZ}$ recorded significant decrease in the final body weights which is consistent with [20], who added that this decrease is due to failure of this group to gain body weights throughout the experiment. Such weight gain reduction in MMZ-group could be explained by the fact that thyroid hormones are essential for growth stimulation and their diminished levels may be associated with retarded weight gain in addition to diminished food intake ${ }^{[26]}$.

Regarding the thyroid hormones assessment, thyroidectomy and MMZ-treated groups showed significant decrease in serum concentrations of T3 and T4 in comparison with other tested groups, these results were consistent with ${ }^{[21]}$.
The current study revealed normal splenic architecture in control group I, II and III (thyroidectomy group). These results were in parallel with the studies of ${ }^{[24]}$. It was stated that hypothyroidism itself may create protective role against oxidative stress and tissue damage ${ }^{[3]}$. It was added that hypothyroidism can increase synthesis of polyunsaturated fatty acids within the plasma membrane; this lipid change is able to stop lipid peroxidation and diminish cellular damage $^{[27]}$.

In contrast MMZ- treated group illustrated the alternation in rat's spleen structure following administration of MMZ, which revealed vacuolated cells with fragmented apoptotic nuclei within the white pulp. According to the study of Kannak and Jain ${ }^{[28]}$ such apoptotic changes could be attributed to the oxidative stress status which accompanying MMZ toxicity and resulted in apoptosis and alternation in gene expression.

Moreover, MMZ group revealed numerous areas which contained debris of ruptured degenerated cells within the white pulp. It was reported that such cellular damage 
attributed not only to the chemical structure of MMZ but also to excess the production of ROS with disruption of the redox environment of the cell that altered the cell physiological state, leading finally to cellular damage ${ }^{[29]}$.

The results of this study showed an apparent decrease of the immuno-reaction for CD4 in MMZ- treated group. Similarly it was assigned that MMZ induced oxidative stress status and increased lipid peroxidation may be responsible for such reduction in $\mathrm{T}$ lymphocytes and macrophage ${ }^{[30]}$. Also, it was stated that immunosuppressive effects of ATDs may play role in reducing the number of CD4-positive helper T cells, CD19-positive B cells and natural killer cells ${ }^{[6]}$.

Ki67 is a popular nuclear antigen excessively used as a marker of proliferating cells and expressed in G1, G2 and $\mathrm{S}$ phases of the cell cycle but not in $\mathrm{G} 0^{[31]}$. Our results showed remarkable increase in Ki67 immuno-reaction in MMZ-treated group especially in germinal centers. However, NSO co administration showed reduced Ki67 immuno-reaction in comparison with MMZ-treated group.

Germinal centers are the sites where memory B cells and plasma cells secreting antibodies are normally generated $^{[32]}$, and its development is considered a mirror of enhanced antibody responses to certain antigens which are most likely self-proteins and not pathogens but these antigenic proteins still unclear ${ }^{[3]}$. Wolford et al., ${ }^{[33]}$ claimed that reactive metabolites from thiourea derivatives of $\mathrm{MMZ}$ may act as modified self-antigens in the ATDs-treated rats as well as in human.

The hematological analysis of MMZ- treated group showed evident reduction in RBC'S count (erythropenia) and WBC's count (leukopenia) which reflected the immunosuppressive activity of MMZ.

These results are parallel with those of Fukui et al., ${ }^{[20]}$ who stated that MMZ affects hematopoiesis process with subsequent reduction in blood cells formation and lower total leukocytes and lymphocytes compared to the normal one.

It was referred that the reduction in neutrophils production is due to failure of hematopoietic tissue to supply the peripheral blood with mature granulocytes ${ }^{[34]}$. One of the possible explanations of ATD-induced agranulocytosis is proposed to be an immune-mediated mechanism as antibody formation against mature blood cells ${ }^{[16]}$.

The morphometric results revealed reduction marginal zone thickness. Such results were in accordance with ${ }^{[24]}$.

Thymoquinone the active ingredient of NSO has potent antioxidant, anti-infective and antihistamine effects, In addition to immune modulatory effect ${ }^{[35]}$. So administration of NSO in the present work restored the normal hormones levels. In the same line were the results of ${ }^{[36]}$.

The hisopathological changes recorded in MMZ- treated group showed notable improvement in the histology of the spleen with co-administration of NSO. Such improvement may be explained by the antioxidant properties of NSO in addition to its role in enhancing the functional capabilities of immune system ${ }^{[37]}$. Ali and Blunden ${ }^{[38]}$ investigated that NSO volatile oil has the ability to scavenge free radicals generated during $\mathrm{MMZ}$ administration.

El-Mahmoudy et al. ${ }^{[39]}$ reported that NSO has accelerative effect on cellular respiratory mechanism and thus may enhance mitosis in mitochondria and enables the mitochondrial enzymes which share in biosynthesis of heame; the most remarkable component in erythropoiesis process. This could explain the improvement of blood picture among the group received NSO in combination with MMZ. Furthermore, NSO has potent anti-inflammatory action which in turn decreases neutrophil migration from peripheral blood resulting in increase in neutrophils in group IV.

\section{CONCLUSION}

It was concluded that MMZ administration strongly disturb the histological structure of the spleen with lowering of hematopoiesis and NSO can help in ameliorating such effects.

\section{ABBREVIATIONS}

MMZ: methimazole, ATDs: antithyroid drugs, NSO: nigella sativa oil, ROS: reactive oxygen species.

\section{CONFLICT OF INTEREST}

There are no conflicts of interest.

\section{FUNDING}

This study was not funded by any source.

\section{REFERENCES}

1. Yang, J., Zhang, J., Xu, Q., Sheng, G. P., Weng, W. W., \& Dong, M. J. Unusual synchronous methimazole-induced agranulocytosis and severe hepatotoxicity in patient with hyperthyroidism: a case report and review of the literature. International journal of endocrinology; 2015.

2. Bergman,U., Brittebo, E.B. Methimazole toxicity in rodents: covalent binding in the olfactory mucosa 
and detection of glial fibrillary acidic protein in the olfactory bulb. Toxicol Appl Pharmacol 1999; 155 (2): 190-200.

3. Cano-Europa, E., Blas-Valdivia, V., Franco-Colin, M., Gallardo-Casas, C. A., \& Ortiz-Butrón, R. Methimazole-induced hypothyroidism causes cellular damage in the spleen, heart, liver, lung and kidney. Acta histochemica 2011; 113(1), 1-5.

4. Cooper, D.S. Antithyroid drugs. The New England Journal of Medicine 1984; 311(21):1353-62.

5. Bandyopadhyay, U., Biswas, K., Banerjee, R.K. Extrathyroidal actions of antithyroid thionamides. Toxicol lett 2002; 128:117-127.

6. Cooper, D.S. Antithyroid drugs. The New England Journal of Medicine 2005; 352(9):905-17.

7. Heidari, R., Niknahad, H., Jamshidzadeh, A., Eghbal, M. A., \& Abdoli, N. An overview on the proposed mechanisms of antithyroid drugsinduced liver injury. Advanced pharmaceutical bulletin 2015; 5(1), 1 .

8. Cooper, D.S., Goldminz, D., Levin, A.A., Ladenson, P.W., Daniels, G.H., Molitch, M.E., et al. Agranulocytosis associated with antithyroid drugs. Effects of patient age and drug dose. Ann Intern Med 1983; 98(1):26-9.

9. Erve, J.C. Chemical toxicology: reactive intermediates and their role in pharmacology and toxicology. Expert Opin Drug Metab Toxicol 2006; 2(6):923-46.

10. Heidari, R., Babaei, H., Eghbal, M.A. Ameliorative effects of taurine against methimazole-induced cytotoxicity in isolated rat hepatocytes. Sci Pharm 2012; 80(4):987-99.

11. Valko, M., leibfritz, D., Moncol, J., Cronin, M.T.D., Mazur, M., Telse, J. Free radicals and antioxidants in normal physiological functions and human disease. Int J Biochem Cell Biol 2007; 39:44-84

12. Iwasaki, A., Medzhitov, R. Regulation of adaptive immunity by the innate immune system. Science 2010; 327:291-295.

13. Abass, M. A., Selim, S. A., Selim, A. O., El-Shal, A. S., \& Gouda, Z. A. Effect of orally administered zinc oxide nanoparticles on albino rat thymus and spleen. IUBMB life 2017; 69(7), 528-539.
14. Gao, J. X., Liu, X., Wen, J., Zhang, H., Durbin, J., Liu, Y., \& Zheng, P. Differentiation of monocytic cell clones into $\mathrm{CD} 8 \alpha+$ dendritic cells (DC) suggests that monocytes can be direct precursors for both $\mathrm{CD} 8 \alpha+$ and $\mathrm{CD} 8 \alpha-\mathrm{DC}$ in the mouse. The Journal of Immunology 2003; 170(12), 5927-5935.

15. Kobayashi, S., Noh, J. Y., Mukasa, K., Kunii, Y., Watanabe, N., Matsumoto, M., \& Sugino, K. Characteristics of agranulocytosis as an adverse effect of antithyroid drugs in the second or later course of treatment. Thyroid 2014; 24(5), 796-801.

16. Arimura Y. Drug-induced ANCA-associated vasculitis. Saishin Igaku. 2013; 68: 252-258.

17. Hidayati, T., Habib, I., \& Akrom, A. Antiimmunotoxic ofBlack Cumin Seed Oil(Nigella sativa Oil) in DMBA (Dimethylbenzantracene)Induced Mice 2015.

18. Badary, O. A., Abd-Ellah, M. F., El-Mahdy, M. A., Salama, S. A., \& Hamada, F. M. Anticlastogenic activity of thymoquinone against benzo (a) pyrene in mice. Food and Chemical Toxicology 2007; 45(1), 88-92.

19. Tenorio-Velázquez VM, Barrera $\mathrm{D}$, Franco $\mathrm{M}$, Tapia E, Hernández-Pando R, Medina-Campos, O.N., Pedraza-Chaverri, J. Hypothyroidism attenuates protein tyrosine nitration, oxidative stress and renal damage induced by ischemia and reperfusion: effect unrelated to antioxidant enzymes activities. BMC Nephrol 2005; 6:12.

20. Fukui, M., Fukui, N., Sakai, K., Hasegawa, Y., Nagasaki, S., Shibata, S., \& Hisada, S. Spleenspecific development of germinal centers in rats treated with antithyroid drugs. Journal of toxicologic pathology 2013; 26(4), 375-384.

21. Gazia, M. A. Antithyroid drug or hypothyroidism causes cellular damage in the renal cortex of adult male albino rats: a histological and immunohistochemical study. Egyptian Journal of Histology 2013; 36(3), 636-645.

22. Chanarin, I., Cairns, J., and Waters, D. Coulter blood count. J. Clin. Pathol.1973; 26, 978.

23. Bancroft, J. D., and Layton, C. The hematoxylin and eosin. Bancroft's Theory and Practice of Histological Techniques, Expert Consult: Online and Print 2012; $7^{\text {th }}$ edn. p. 173, Elsevier: Amsterdam, Netherlands. 
24. Hafez,M.S.Histologicalandimmunohistochemical study on the effect of noise stress on the spleen of adult albino rat and the possible role of Ginkgo biloba extract. Egyptian Journal of Histology 2013; 36(3), 546-555.

25. Sefi, M., Amara, I. B., Troudi, A., Soudani, N., Hakim, A., Zeghal, K. M., \& Zeghal, N. Effect of selenium on methimazole-induced liver damage and oxidative stress in adult rats and their offspring. Toxicology and industrial health 2014, 30(7), 653-669.

26. Čakić-Milošević, M., Korać, A., \& Davidović, V. Methimazole-induced hypothyroidism in rats: effects on body weight and histological characteristics of thyroid gland 2004.

27. Hataya, Y., Igarashi, S., Yamashita, T., Komatsu, Y. Thyroid hormone replacement therapy for primary hypothyroidism leads to signifcant improvement of renal function in chronic kidney disease patients. Clin Exp Nephrol 2012; 1-7.

28. Kannak, K., Jain, S.K. Oxidative stress and apoptosis. Pathophysiology 2000; 7:153-163.

29. Angermüller, S., Islinger. M., Völk1, A. Peroxisomes and reactive oxygen species, a lasting challenge. Histochem Cell Biol 2009; 131:459-463.

30. Ben Amara, I., Troudi, A., Garoui, E., Hakim, A., Boudawara, T., Zeghal, K.M., Zeghal, N. Protective effects of selenium on methimazole nephrotoxicity in adult rats and their offspring. Exp Toxicol Pathol 2011; 63:553-561.

31. Bruno, S. and Darzynkiewicz, Z. Cell cycle dependent expression and stability of the nuclear protein detected by Ki-67 antibody in HL-60 cells. Cell Prolif. 1992; 25:31-40.

32. Allen, C.D., Okada, T., and Cyster, J.G. Germinal center organization and cellular dynamics Immunity 2007; 27: 190-202.
33. Wolford, A., McDonald, T.S., Eng, H., Hansel, S., Chen, Y., Bauman, J., Sharma, R., and Kalgutkar, A.S. Immune-mediated agranulocytosis caused by the cocaine adulterant levamisole: a case for reactive metabolite(s) involvement. Drug Metab Dispos.2012; 40: 1067-1075.

34. Zahran, W. M., El-Feki, M. A., Gabri, M. S., \& Ebaid, H. The anticarcinogenic effect of the black seeds (Nigella sativa) on leukemia. 1-Bone marrow and blood picture. El-Minia Sci. Bul, 1996; 9, 1-19.

35. Randhawa, M. A., and Al-Ghamdi M. S. "A review of the pharmaco-therapeutic effects of Nigella sativa," Pakistan J. Med. Res. 2002; vol. 41, no. 2.

36. Nickavar, B. Mojab,F. Javidnia,K. and M. A Amoli, "Chemical composition of the fixed and volatile oils of Nigella sativa L. from Iran," J. Naturforsch, 2003; vol. 58, no. 9-10, pp. 629-631.

37. Salem, M. L. Immunomodulatory and therapeutic properties of the Nigella sativa L. seed. International immunopharmacology 2005; 5(1314), 1749-1770.

38. Ali, B. H., and Blunden, G. Pharmacological and toxicological properties of Nigella sativa. Phytotherapy Research: An international journal devoted to pharmacological and toxicological evaluation of natural product derivatives 2003; 17(4), 299-305.

39. El-Mahmoudy, A., Matsuyama, H., Borgan, M. A., Shimizu, Y., El-Sayed, M. G., Minamoto, N., \& Takewaki, T. Thymoquinone suppresses expression of inducible nitric oxide synthase in rat macrophages. International immunopharmacology 2002; 2(11), 1603-1611. 


\section{الملخص العربى}

الدور التحوطي لزيت حبة البركة في السمية المرتبطة بالميثمازول على بنية الطحال في

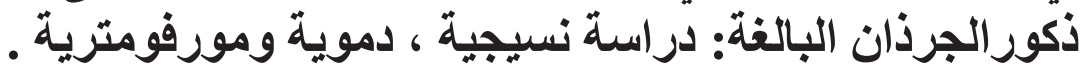

مروة محمود أحمد1, منال محمد مرسي1 ,ريهام محمد مرسي²

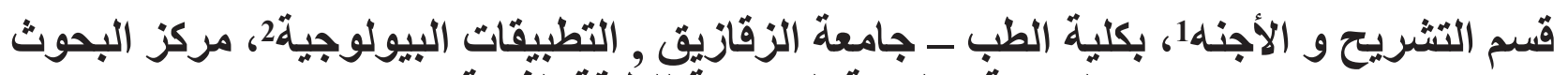
النووية ، الهيئة المصرية للطاقة الذرية

خلفية البحث: ميثيمازول (MMZ) ، كان الدو اءو المفضل في علاج فرط نشاط الغدة الدرقية البشري لعدة عقود ، ولكن تناوله

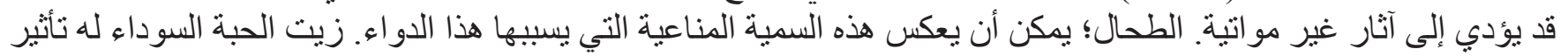

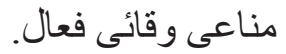
الهذف من البحث: تهدف الدر اسة الحالية إلى تحديد التغير ات في بنية الطحال و معاملات الدم نتيجة تناول عقار ميثيمازول وما

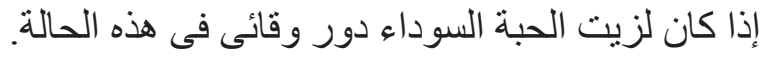

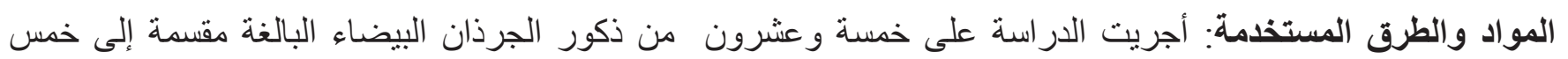

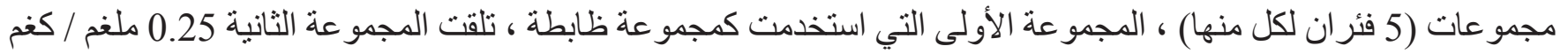

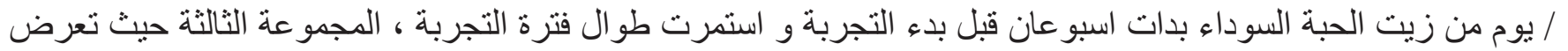

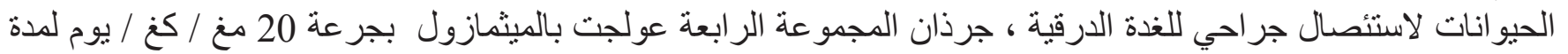

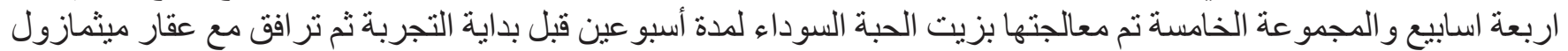

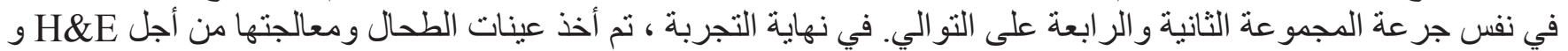

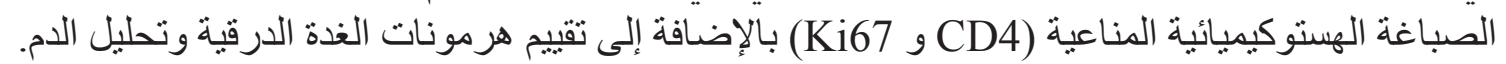

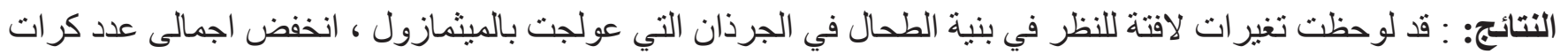

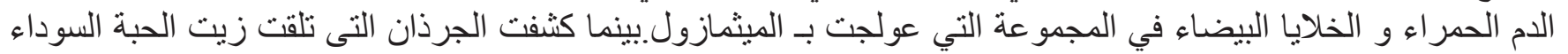

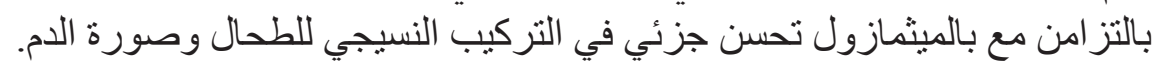
الاسنتاج: عقار الميثمازول له تأثثير و اضح على على له تأثثير سمى مناعى واضح على على الطحال و زيت الحبة السوداء له تأثثر وقائى وثيق الصلة. 